\title{
LA CRIPTOPALEONTOLOGÍA EN LOS LAPIDARIOS GRIEGOS APÓCRIFOS
}

\author{
Eladio LIÑÁN
}

Área y Museo Paleontológico de la Universidad de Zaragoza. Departamento de Ciencias de la Tierra. Facultad de Ciencias. 50009 Zaragoza

Liñán, E. 2005. La criptopaleontología en los lapidarios griegos apócrifos. [The Cryptopalaeontology of the apocryphal Greek lapidaries.] Revista Española de Paleontología, 20 (2), 119-126. ISSN 0213-6937.

\begin{abstract}
The study of the Greek manuscripts on the stone attributes (apocryphal Greek lapidaries), preserved at the present day, evidences that description of fossils are present between the different types of stones referenced, as well as stony remains of recent animals. From an historical point of view, they contains one of the most primitive appellations and descriptions of fossils, and are a fundamental source to apprehend the meaning given to the fossils by the ancient cultures.
\end{abstract}

Key words: Cryptopalaeontology, lapidary, history of Palaeontology, farmacopoeia, mythology.

\section{RESUMEN}

El estudio de los diversos manuscritos griegos referentes a las propiedades de las piedras (lapidarios griegos apócrifos) que han llegado hasta nosotros indica que entre las diferentes clases de piedras descritas se encuentran fósiles y restos pétreos de animales actuales. Los lapidarios constituyen una de las más antiguas denominaciones y descripciones de fósiles y son una fuente fundamental para conocer el significado dado a los fósiles por las culturas antiguas.

Palabras claves: Criptopaleontología, lapidario, historia de la paleontología, farmacopea, mitología.

\section{INTRODUCCIÓN}

Los lapidarios son un tipo especial de textos literarios, obras que describen y dan nombre a una relación de piedras que, como los minerales o las gemas, siempre se han destacado entre los elementos propios de la Naturaleza por su especial forma, brillo o color y a las que la tradición antigua adjudicó propiedades mágicas y curativas. Los primeros textos procedieron de Mesopotamia y Persia pasaron luego a la Grecia clásica y, más tarde, fuertemente impregnados de la tradición astrológica caldeoegipcia pasaron a occidente a través de la cultura árabe. Este énfasis en las propiedades mágicas los diferencia de las obras más propiamente farmacológicas de Hipócrates, Dioscórides y Galeno donde se encuentran también referencias a los minerales y sus subproductos utilizados como remedios, pero sin la connotación mitológica o astrológica de los lapidarios.

La mayor parte de los textos originales de los lapidarios antiguos se han perdido pero se conocen retazos de su contenido por haber sido fuentes de obras posteriores entre las que destacan la "Historia Natural" de Plinio "el Viejo" (siglo I), las "Etimologías" de Isidoro de Sevilla (siglo VII) y el códice "Lapidario del rey Alfonso X, El Sabio, de Castilla” (siglo XIII); así como por diversos manuscritos realizados por copistas a partir del siglo XIV de cinco textos apócrifos incluidos bajo el nombre de Lapidarios griegos por estar escritos en esta lengua. Son el "Lapidario órfico" o "Lithica Orphéôs", el "Lapidario Kerygmata" u "Orphéôs Líthica Kêrygmata" (epítome o resumen del "Lapidario órfico"), el "Lapidario Sócrates y Dionisio" o "Socrátous Dionísou perì líthôn", el "Lapidario náutico" y el "Lapidario Damigerón-Évax". Tanto el primero como el último de éllos (único conservado en latín y supuestamente compuesto por el mago Damigerón, y acompañado por una carta del rey Évax de Arabia al emperador romano Tiberio), por su similitud, debieron ser obras fundadas en un anterior texto griego del que conservaba algunos fragmentos el médico Etio de Amida (Rose, 1875). Aunque su cronología es discutida, hay un acuerdo general en que estos lapidarios griegos recogen algunas de las referencias escritas más antiguas sobre rocas, minerales y fósiles. 
Aunque existe otro lapidario griego denominado " $\mathrm{Pseu}$ do-Hipócrates", copia manuscrita del siglo XV conocida como "Parisinus Graecus" 2316, éste sólo resume el conjunto del "Lapidario Kerygmata" y del "Lapidario Sócrates y Dionisio", así como noticias neo-griegas que no se consideran aquí. Asimismo, el "Lapidario Pseudo-Dioscórides" incluído en el códice manuscrito Matritensis N110, no es sino una colección de noticias apoyadas en la obra de Dioscórides (siglo I) y en la enciclopedia de Etio de Amida (siglo VI), complementada con los sinónimos árabes de las piedras.

La mayoría de las piedras citadas en estos lapidarios son minerales y rocas, pero también hay fósiles, algunas veces difíciles de separar de los organismos actuales como son los corales, cuyos esqueletos mineralizados quedan expuestos tras la putrefacción de los tejidos blandos. Ello daría pie a la confusión, frecuente en el mundo clásico, de la petrificación de estos animales una vez muertos, lo que les confirió un cierto halo mágico.

El "Lapidario órfico" (alusión a Orfeo, célebre poeta y músico tracio que según la mitología griega bajó a los infiernos en busca de su esposa Eurídice) es un poema apócrifo griego construido en hexámetros del que se conservan seis manuscritos. Aunque de cronología no bien aquilatada, es considerado previo al siglo II a. C. En él se incluye, bajo la denominación de Piedra de Cornamenta de Ciervo, Ostrita, Piedra de Escorpiones y Corsita (Piedra de Cabeza), la posible referencia a fósiles y a sus propiedades mágico-curativas. Algunas de estas piedras son también citadas en el "Lapidario Kerygmata".

Siete manuscritos conservan en prosa el "Lapidario Kerygmata" y el "Lapidario Sócrates y Dionisio", frecuentemente copiados unos detrás de otros. El primero es de época bizantina y el segundo de probable época imperial y procedencia egipcia. En el "Lapidario Kerygmata", se incluyen referencias, al igual que en el "Lapidario órfico", aunque más resumidas, a la piedra de Cornamenta de Ciervo, la Ostrita, Piedra Corsita, Piedra de Gagates, Piedra de Escorpión y Coral. En el "Lapidario Sócrates y Dionisio" se encuentra la Piedra de Mirra y una serie de piedras (47-53) pretendidamente extraídas del interior de animales vivos (piedra de golondrina, de halcón, de dragón, de topo, de lagarto, de sapo, de hiena) a los que se parecen ya sea por su color o forma; salvo la de sapo, que se extrae de una rana y se parece a una tortuga.

El "Lapidario náutico" se conserva en tres copias manuscritas: "Parisinus Graecus" 2424, 2421 y 2422; la primera del siglo XIV y las dos restantes del siglo XVI. Es el que menor número de piedras recoge. Destaca por la parquedad de sus descripciones. Se concibe como un lapidario temático para navegantes, en el que las piedras se consideran a modo de talismanes frente a las inclemencias de la navegación.

En el "Lapidario Damigerón-Évax", se citan la Piedra Arábiga (que según Plinio es marfil fósil y según Dios- córides se parece al marfil) cuyo signo zodiacal es Virgo y se extrae del ojo de una tortuga de la India, y la Piedra Alectoria que se extrae de las gallináceas (también cf. Plinio XXXVI 144), tiene aspecto cristalino y metida en al boca hace invencible a cualquier soldado o atleta.

Está ampliamente estudiado que aves y reptiles pueden ingerir piedras para facilitar la digestión. Son denominadas gastrolitos y fácilmente reconocibles por su pulido natural incluso en yacimientos fósiles, donde los más espectaculares por su tamaño son los gastrolitos de dinosaurios. Pero en el lenguaje críptico de los lapidarios es difícil saber si se trata de auténticas piedras encontradas en animales vivos, o de piedras parecidas por su color a animales, o de las frecuentes cristalizaciones que se producen en los huecos de los esqueletos fósiles, o incluso de auténticos especímenes fósiles. No es fácil creer que auténticas piedras se extraigan del ojo de una tortuga, de la cabeza de los halcones o del corazón de las hienas como sugieren algunos lapidarios, pero se conoce que muchos braquiópodos fósiles sí que tienen forma de golondrina o de pájaro y han dado lugar a numerosas leyendas (Liñán, 1998). Aunque los animales construimos, mediante inducción genética, esqueletos de muy diversa composición química y mineralógica, y somos capaces de producir piedras por diferentes mecanismos y en situaciones patológicas (por ejemplo las perlas de los ostréidos, los otolitos de crustáceos o la acumulación de fosfatos y oxalatos cálcicos en el sistema digestivo-excretor de vertebrados), lo más plausible es que la continuada transmisión oral de las fuentes y de las copias escritas, con sus sesgos y adiciones locales, haya producido una confusa mezcolanza que es típica de los lapidarios y bien conocida de los estudiosos, al comparar las diferentes copias.

A continuación, veremos la relación de piedras que presumiblemente aluden a fósiles y su textual utilización mágico-medicinal en estas obras, según la edición exquisitamente preparada por Halleux \& Schamp (1985) con los diferentes manuscritos que se conservan de cada lapidario. También es de reseñar la edición española del "Lapidario órfico" preparada por Calvo Deleán (1990). A ello se añadirá un pequeño comentario ilustrativo de su empleo histórico y de la pervivencia de su nombre en algunas tradiciones orales españolas.

\section{LOS FÓSILES CONTENIDOS EN LOS LAPIDARIOS}

\section{Piedra de Cornamenta de ciervo}

Cornamenta de Ciervo ("Lapidario órfico", v. 244259): Busca también esta maravilla, la cornamenta de ciervo y con ella estarás próximo a los inmortales, pues la mente de los celestiales sonríe al ver la obra de la muy artística naturaleza. Ella es sin duda una cornamenta: 
análoga a la que brota sobre la cabeza de los ciervos de patas largas. No hay punto del cráneo del que brote una piedra. Y esta cornamenta tiene siempre la dureza de una piedra. No se podría saber si es una cornamenta verdadera o un mineral, antes de tocarla y descubrir que efectivamente es una piedra sin defecto. Siempre hará crecer espeso cabello sobre tu cabeza, por lisa que pueda ser. Si la trituras con aceite y frotas tus sienes todos los días con este ungüento, enseguida volverá a florecer sobre tu cabeza una espesa cabellera. Y cuando de su robusto brazo un hombre lleve al lecho nupcial a una doncella, que tenga con él esta piedra como prenda de placer amoroso, ella sujetará a ambos con irrompibles lazos hasta la extrema vejez, cada día de su vida.

Esta descripción, idealizada por el poeta, deja pocas dudas de que se traten de cornamentas fósiles de cérvidos (los cérvidos no tienen auténticos cuernos sino apófisis craneales denominadas cuerna o cornamenta) que tan abundantes son en los estratos del Terciario y Plioceno de Grecia y de toda la región Mediterránea, sin poder descartar que se incluyan otros vertebrados con apófisis craneales. En la antiquísima farmacopea China se diferencian por su mayor poder curativo los dientes de dragón (dientes y cornamentas fósiles) de los huesos de dragón, que tiene un precio más bajo (Buffetaut, 1991). Como es lógico de esperar entre dos culturas separadas, las cornamentas fósiles se usaron en China, no contra la alopecia y males de amor sino como pretendido remedio para otras enfermedades como las afecciones cardíacas y epilepsias.

En el "Lapidario Kerygmata" la descripción es parecida: La piedra de cornamenta de ciervo. Ella también toma su nombre de su apariencia. Se asemeja, en efecto, a una cuerna de ciervo y a la vista no se podría distinguir fácilmente si se trata de una cornamenta o de piedra, habiéndose de tener en la mano para identificarla verdaderamente por su resistencia al choque y su dureza. Sus efectos son, llamémosle, asombrosos si se la tritura, se la mezcla con aceite y se la unta al cráneo de un calvo, pues inmediatamente nuevos cabellos brotarán, y el hombre, que era calvo, terminará con melena. Además, da también a los recién casados el amor mutuo y la concordia si se la porta, y mantiene su deseo hasta la vejez.

La cornamenta de ciervo aparece como componente de diferentes fórmulas magistrales en la obra de Johannitius (Hunayn B. Ishâk) médico jefe de la corte califal de Bagdag (808-873), del médico tunecino Ibn al-Yazâr (m 1004) y del médico cordobés Abulcasis (cf. Arvide Cambra, 1996) que vivió entre el año 936 y el 1013. Otra referencia al empleo generalizado de astas de ciervo quemadas se encuentra en el tratado de magia medieval denominado "Picatrix" traducido en 1256 del árabe por Alfonso X el Sabio (Bakhouche et al., 2003). Cortadas y quemadas como remedio para las picaduras de animales ponzoñosos y la rabia (quizá por su poder absorbente) se encuentran también en la obra de Torrubia (1754: 29), bajo la denominación de Piedra de Culebra española o de Serpiente. La cornamenta de ciervo transformada en virutas fue también usada en albeitería como remedio en oftalmología y contra las inflamaciones o tumores del cuello y espalda de las caballerías (García Cabero, 1775: 108 y 289). Las cornamentas de los rebaños de alces que crían los nativos de los Montes Sayan en la frontera ruso-siberiana con Mongolia son muy apreciados en botica por los chinos y tibetanos que los compran a alto precio cuando aún están cubiertos de pelusa. Una vez hervidas y secas reciben el nombre de panti. ¿Constituyen estas prácticas una rememoración del empleo de cornamentas fósiles en la farmacopea lapidaria? Es posible. El polaco Ferdynand Ossendowski, químico especialista en minas de oro y yacimientos de carbón que sirvió en el ejército ruso y que fue enviado durante la primera guerra mundial a Mongolia, escribe que en 1920, en medio de la guerra civil rusa, el Buda vivo Su Santidad Djebtsung Damba Hutuktu Jan, Bogdo Gheghen, pontífice de Ta Kure que residía en Urda (Mongolia) tenía un museo de obsequios personales en una vitrina cerrada con una cerradura de plata. Entre los objetos más apreciados se encontraban astas de ciervo milagrosas (Ossendowski, 1958). Bien pudiera ser ésta una referencia críptica a cérvidos fósiles en la línea de los lapidarios porque, si no, es difícil creer que fueran algo tan especial para el Buda vivo, pues, como ya se ha visto, la cornamenta de cérvidos actuales era bien conocida y abundante en Asia, donde hoy su empleo sigue siendo frecuentemente en la medicina tradicional.

En mi opinión, todo ello parece indicar, razonablemente y aunque sólo sea de una manera circunstancial, que la cornamenta de ciervo fósil fue conocida y utilizada como remedio por sus pretendidos poderes mágicos desde tiempos remotos, y que su referencia críptica se encuentra en los antiguos lapidarios. El posterior reemplazamiento por cornamenta de ciervo actual en la praxis mágico-medicinal, pudo deberse a la relativa escasez de estos fósiles.

\section{Ostrita}

Ostrita ("Lapidario órfico", v. 344-346): Yo recomiendo, otras veces, tomar una porción de vino puro y de ostrita molida: esta piedra, yo lo sé, suprime el dolor.

Etimológicamente <ostrites $>$ del griego <óstreon $>$ alude a una ostra petrificada y, sin duda, por extensión a conchas fósiles, con las que ha venido siendo relacionada esta piedra (Halleux \& Schamp, 1985; Calvo Deleán, 1990). El hallazgo de una nave naufragada del siglo XIV a.C. frente a las costas de Turquía cuyas bodegas contenían un cargamento de conchas marinas fósiles (cf. Mayor, 2000) tendría una buena explicación en este contexto. Este interés comercial de las conchas fósiles, apoya desde mi punto de vista la amplia utilización que tuvieron como remedio en medicina, sin que se pueda descartar una relativa valoración por localidades y especies morfológicas, como ocurre con otras piedras, que hicieran rentable su traslado en barco. 
Una alusión similar como remedio se encuentra en el "Lapidario Kerygmata", 15: La piedra llamada Ostrita, molida y puesta con el vino es analgésica; es decir, hace cesar los dolores de todo sufrimiento.

La piedra Ostracita (lapis ostrachitis), citada en el "Lapidario Damigerón-Évax" como representativa del signo Capricornio, pudiera ser la misma pero la referencia que se hace no da ninguna prueba, pues sólo cita las figuras zoomorfas que se deben grabar mágicamente sobre ella. Plinio (XXXVII 177, XXXVI 139) es el único que separa Ostrita y Ostracita como dos piedras distintas, aunque es probable que sean una misma denominación procedente de dos fuentes distintas.

Los ostreidos fósiles son conocidos en los círculos científicos españoles, al menos desde del siglo XVIII, como Ostracita (Río,1795). Un tipo de ostreido de los terrenos cretácicos de Aragón y Valencia es conocido vulgarmente como Oreja de Moro (Cavanilles, 1797) y más localmente como Oreja de Judío (Fig. 1).

\section{Piedra de Escorpiones}

Piedra de Escorpiones ("Lapidario órfico", v. 494497): Escorpión, que una piedra llevara el mismo nombre que tú demuestra que el soberbio Orion lo descono- cía, pues creo que, cuando tenía sus pies traspasados por dolores lacerantes, habría deseado más poseer la piedra que su constelación.

Alusión similar como remedio se encuentra en el " $\mathrm{La}$ pidario Kerygmata", 18: Piedra llamada scorpios, por homonimia con el reptil (sic), que tiene, dicen, poder contra los escorpiones.

Muy probablemente ambos escritos hacen referencia al grupo fósil de los trilobites, artrópodos extinguidos que poblaron las rocas marinas de la Era Paleozoica. Esta suposición la fundamento en tres observaciones. Primero, los trilobites eran ya conocidos y recolectados por el hombre de Cromagnon en el Paleolítico como sugiere el hallazgo en cuevas del sur de Francia de trilobites de probable procedencia alemana (Taton, 1966). Segundo, los trilobites son, con mucho, los artrópodos fósiles más frecuentes en el registro geológico y suelen tener capacidad de enrollamiento haciéndose, así, parecidos a los escorpiones que enrollan el abdomen al sentirse atacados. La tercera observación la constituyen las diferentes denominaciones comunes que recibieron en España. Torrubia (1754: XIII, 83, Lám. III fig. 4) cita y figura como piedras de cangrejo españolas (Fig. 2) los primeros trilobites españoles, procedentes del Ordovícico de Molina de Aragón (Guadalajara),

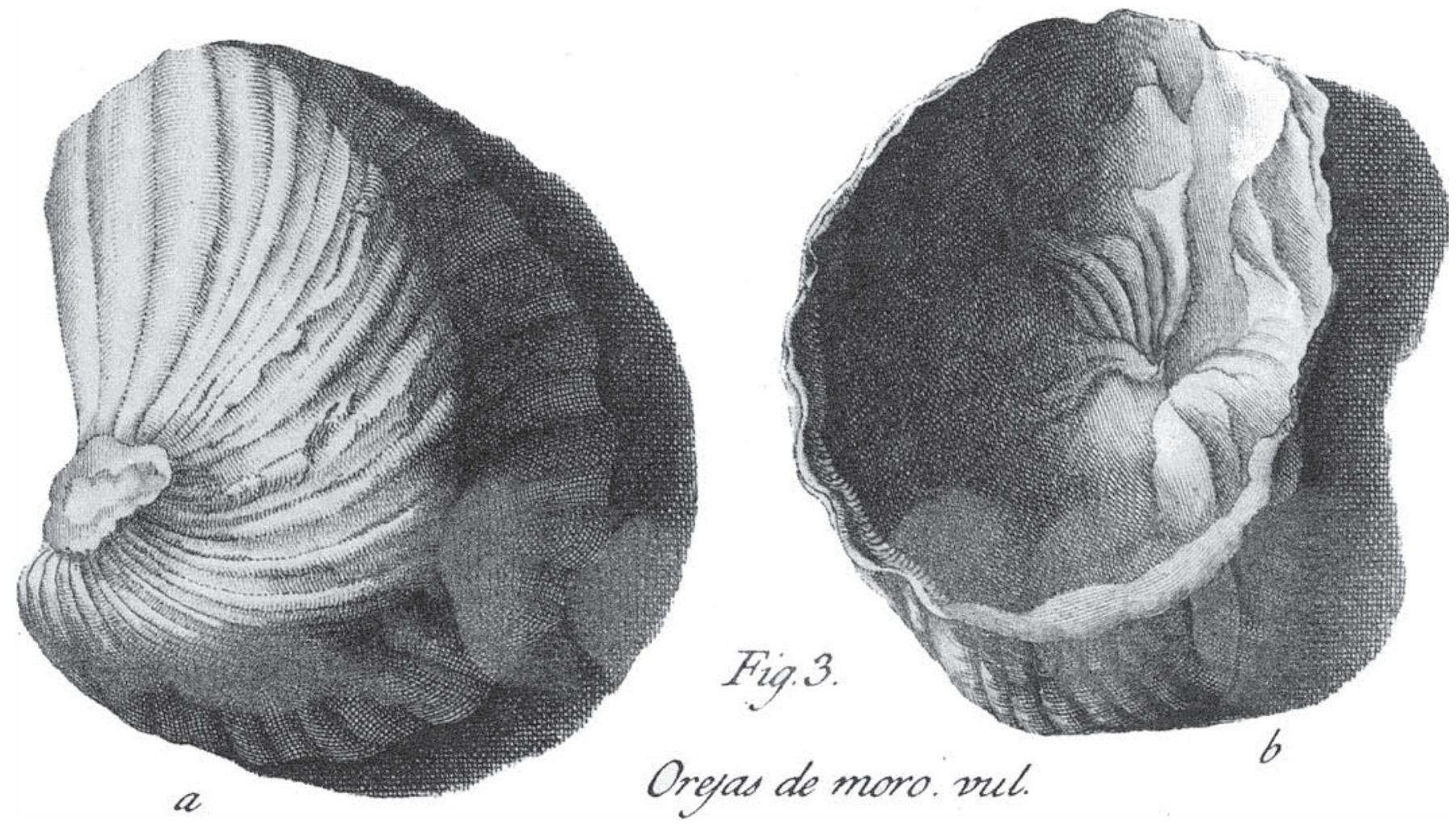

Figura 1. Primera figuración de una Ostrita española representada por el ostreido Exogyra flabellata del Periodo Cretácico de las provincias de Castellón y Valencia, con el nombre vulgar de "orejas de moro" con el que se le conocía. Tomada de Cavanilles (1795-1797).

The first figuration of a Spanish Ostrite represented by the ostreid Exogyra flabellata of the Cretaceous Period from Castellón and Valencia provinces, under the trivial name of "orejas de moro". After Cavanilles (1795-1797). 


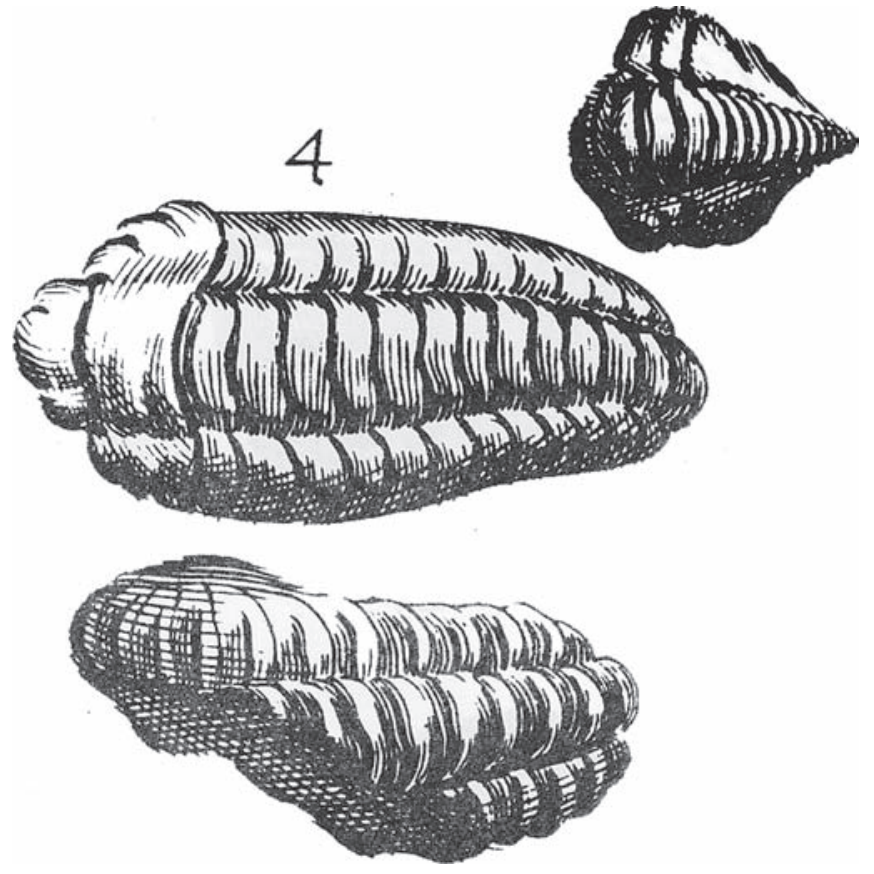

Figura 2. Fósiles de la obra de Torrubia (1754: Lám. III fig. 4) mostrando tres ejemplares de trilobites del Ordovícico de Molina de Aragón que denomina "piedras españolas de cangrejos" (Op. cit.: 83). Probablemente, la primera representación española de la Piedra de Escorpión citada en los lapidarios más antiguos. Fossils from Torrubia's book (1754: Plate III fig. 4) showing thre specimens of Ordovician trilobites from Molina de Aragón which he named spanish stones of crabs (Op. cit.: 83). Probabbly the first Spanish figuration of the Scorpion Stone referred into the oldest lapidaries. que diferencia bien de las piedras Indianas del cangrejo de China y Filipinas que son auténticos cangrejos fósiles y que él conoció previamente en su visita a las misiones (Fig. 3). Esta pudo ser la razón por la que a los trilobites les llamó cangrejos y no escorpiones. También en el pueblo de Murero (Zaragoza), los abundantes trilobites del Cámbrico Medio son conocidos por los naturales como "cabezones" por ser mayor el tamaño que tiene el cefalón respecto al resto del cuerpo (igual que acontece en los escorpiones, portadores de un abultado cefalotórax respecto al delgado abdomen). Curiosamente, los trilobites del Cámbrico Inferior de San Nicolás del Puerto (Sevilla) son llamados por los lugareños "escorpiones de piedra" por su cuerpo segmentado; y en Constantina (Sevilla) "hormigones de piedra". Finalmente, los trilobites solían vivir formando comunidades de numerosos individuos que dejaban su esqueleto al mudar o al morir sobre el fondo en el que fosilizan, dando lugar a frecuentes acumulaciones en la superficie de la roca que bien podrían explicar el plural con se designa a esta piedra en el lapidario.

En uno de los doce trabajos de Hércules, Hera mandó contra el gigante un formidable cangrejo (Cárcino) que el héroe mató con la clava o maza de olivo con nudos. La visión de muchos de los distintos grupos de artrópodos y otros grupos fósiles bien pudieron entremezclarse con las narraciones mitológicas y llegar a conferirles supuestos poderes mágicos (Liñán, 2004).

\section{Piedra de Cabeza o Piedra Corsita}

Piedra de cabeza ("Lapidario órfico" v. 498-509): Él tampoco había oído hablar de la piedra $<$ Korsites $>$ puesto que mezclada con una cabeza de ajo picante, habría
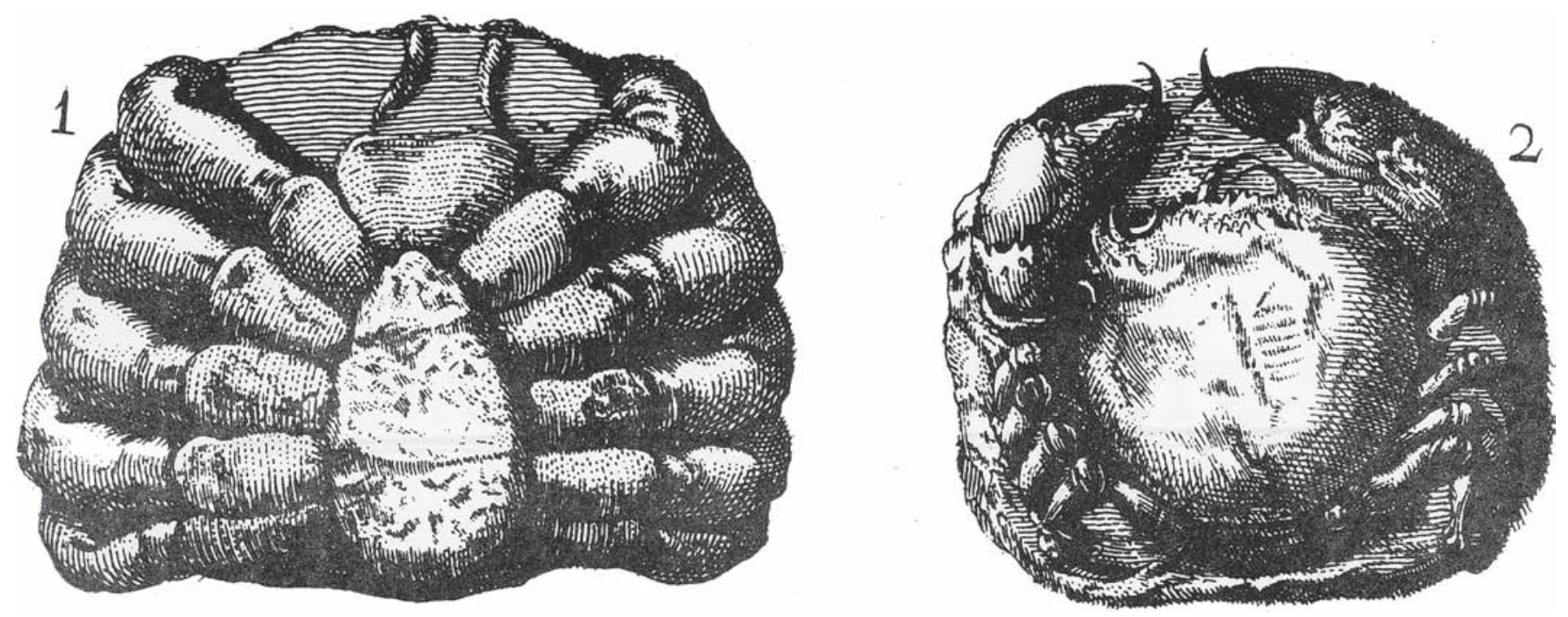

Figura 3. Cangrejos fósiles procedentes de la isla de Haynan en China (fig. 1) e isla de Luzón en Filipinas (fig. 2) figurados por Torrubia (1754: Lám. XIII figs. 1 y 2) y llamados Piedras Indianas de Cangrejos.

Fossils crabs from Haynan Island of China (fig. 1) and Luzón Philippines Island (fig. 2) figured by Torrubia (1754: Lám. XIII figs 1 y 2) and named "crabs indian stones". 
privado bien pronto al escorpión de su poder, arquero de paralizantes saetas. Esta piedra es muy semejante a las sienes de un mortal. Triturada en polvo y disuelta en un vino muy agrio, pone fin, yo lo aseguro, a los efectos del veneno del áspid sanguinario, proveedor de la muerte. $Y$ si se disuelve en una misma cantidad de aceite de rosa un fragmento de la piedra después de cocerla al fuego, el producto ofrece un remedio contra los males de cuello. $Y$ si se mezcla con miel suave, esta piedra elimina las bolsas malignas y los humores que se forman en el vientre de los hombres y que hacen brotar en la ingle, al presionar el abdomen, bubones deformes.

Una alusión similar como remedio se encuentra en el "Lapidario Kerygmata", 19: Piedra llamada corsita. Se la llama así a causa de su similitud con una <korsé>, es decir una cabeza humana. Se dice que triturada con ajo y absorbida, es un remedio contra las mordeduras de escorpiones. Untada con aceite de rosa, detiene los dolores alrededor del cuello. Mezclada con miel y absorbida, limpia el estómago, vacía la hidropesía, cura los bubones.

Es difícil identificar fehacientemente esta piedra, pero por su descripción comparativa antropomorfa parece ser un fósil animal. Como apuntan (Halleux \& Schamp, 1985) corsite es un adjetivo épico de sienes y equivalente al corsoides de Plinio que alude a sienes canas. La combinación de cabeza y sienes que aparece en los textos apunta a que tuviera una aspecto de sienes con cabellos y en este caso, según hacen notar estos autores, podría relacionarse con la piedra anthropocrinus que según el "Lapidario Damigerón-Évax" imita los cabellos del hombre y que veremos a continuación.

\section{Piedra anthropocrinus}

Piedra anthropocrinus ("Lapidario Damigerón-Évax", LIII): La piedra anthropocrinus contiene estrellas desgreñadas como los cabellos del hombre. Esta piedra proporciona liberación del arte mágico y maléfico, si se la lleva al cuello ensartada en un hilo multicolor.

Esta cita se trata en mi opinión de la descripción mas rigurosa y antigua de crinoideos fósiles, cuyo tallo compuesto de piezas calcíticas, articuladas, con orificio central y, frecuentemente, estrelladas, permite su fácil engarzamiento en collares. Su redondeado cáliz, a modo de cabeza, recubierto de braquiolas plumosas orientadas hacia atrás por las corrrientes, recuerdan al aspecto de cabellos largos desmelenados sobre las sienes, al que alude el lapidario.

Los distintos nombres que recibe esta piedra de crinoides fósiles (piedra de cabeza, corsita y antropocrinus) es posible se deba a la diversidad de especies que se conocen, pues es un grupo que aparece en el Paleozoico temprano y cuyos componentes aún se encuentra hoy, cuatrocientos millones de años después, viviendo anclados en los fondos marinos como típicos organismos sésiles, lo que no es sino el tenue residuo del pretérito esplendor del grupo.

\section{Piedra de Mirra}

Piedra de Mirra ("Lapidario Sócrates y Dionisio", 46): La piedra de mirra tiende al verde-amarillo. Molida, produce un olor como el de la mirra. Ella es un medio de seducción, especialmente para las mujeres. Muchos hombres se enamorarán de esta mujer, simplemente bajo el efecto del poder de la piedra. Es un antídoto para las personas envenenadas. Se la distingue frontándola ligeramente.

Según Halleux \& Schamp (1985) es una resina fósil. Este tipo de fósil químico recibe el nombre genérico de ámbar. También está citada por Plinio (XXXVII 174).

Ossendowski (1958) cuenta que cuando visitó en 1920 al Buda vivo que residía en Urda (Mongolia) guardaba en su museo de obsequios personales un trozo de ámbar procedente de las costas del Ártico que pesaba unas diez libras (unos cinco kilos).

\section{Piedra Lyngurium}

Piedra Lyngurium ("Lapidario Damigerón-Évax", XXXI): La piedra lyngurium dota de excelente protección a la casa, pero también a las mujeres embarazadas y a los niños para que no tengan miedo. Ella resiste también al mal real (cálculos en la vesícula) si se la porta o se la bebe en polvo mezclada con vino.

Es una de las más citadas en la antigüedad. Teofastro la describe como orina de lince petrificada. Considerada como ámbar por Dioscórides, Demostrates (según Plinio) y Hesichyos, se podría considerar como una etimología popular para el ámbar de la región de Liguria (cf. Estrabón, IV, 5, 3; IV, 6, 2) cuya capital es Génova.

Según las adiciones al "Lapidario DamigerónÉvax"(supl. 32) es un sinónimo de la Piedra de Lince referida también por el "Lapidario Damigerón-Évax" (XLIII), que muchos llaman ligurium y electrum, y es buena para los dolores de estómago y el reumatismo.

En resumen, parece convincente que ambas denominaciones puedan hacer referencia a diferentes yacimientos geográficos de resinas fósiles, llamadas ámbar, ampliamente conocido y utilizado incluso en occidente desde épocas prehistóricas.

\section{Piedra Odontolycius}

Piedra Odontolycius ("Lapidario Damigerón-Évax", XVIII): La piedra odontolycius, es decir, los dientes del lobo, da suerte y es útil a los soldados, a los cazadores, a los que quieren poseer algo, a los que quieren hacer adivinaciones a través del agua, o por las facultades adivitatorias al ponerla en el fondo de un vaso. Como apoyo, la piedra da a los niños una sólida protección. Son sobre todo útiles a los ladrones que quieren robar los bienes ajenos.

Como usualmente se ha venido interpretando, se trata de dientes fósiles de mamíferos carniceros. Plinio "El Viejo" y Julio "El Africano" ponen énfasis en las virtudes de los dientes de lobo que son tenidos por amuletos que dan velocidad y energía. 


\section{Piedra Gagates}

Piedra Gagates ("Lapidario órfico", v. 474-493; "Lapidario Kerygmata", 17; "Lapidario Damigerón-Évax", XX, LXXII).

Hace referencia al carbón fósil por su descripción, comparación con el pino seco, sus propiedades combustibles y por el efecto pernicioso de sus olores, frecuentemente azufrosos. Probablemente se refiera a lignito.

El carbón fósil ha recibido diferentes denominaciones linguística y según su procedencia geográfica: Piedra Azabache, Piedra Gagates, Piedra de Gagas. Lapis gagates o lapis gagatis, parece hacer referencia a un río de Licia, en Asia menor, tal vez el actual Alagoz (cf. Nicandro, Teríacas, 37; Plinio, XXXVI 141; Dioscórides V 128-129; Galeno XII 203; Isidoro, XVI 4,3). La Piedra de Tracia citada también por Dioscórides, Nicandro, Plinio, Galeno e Isidoro, se tiende más a identificar con un esquisto bituminoso.

\section{Coral}

Coral ("Lapidario órfico", 510-610; "Lapidario Kerygmata", 20; "Lapidario náutico", 5; Piedra de Coral en el "Lapidario Damigerón-Évax", VII).

Aunque en los tres lapidarios referidos se alude siempre al coral actual, no se puede descartar que se incluyeran también corales fósiles, por otra parte, difíciles de diferenciar sin conocimientos taxonómicos suficientes.

El "Lapidario órfico" da cuenta de los cambios de aspecto de los corales vivos y del aspecto pétreo de su esqueleto ya descolorido al morir. El coral es utilizado como remedio para diversas enfermedades y se relaciona mitológicamente con la Gorgonas por su pretendido poder petrificante. El "Lapidario Kerygmata" refiere su utilidad contra las serpientes y sus mordeduras y, entre otras virtudes, el guardar de todo mal en el combate y en los viajes por tierra y mar al que la porta. El "Lapidario náutico" describe al coral como piedra talismán En el "Lapidario Damigerón-Évax" se recogen los grandes poderes mágicos, medicinales y divinos de esta piedra; en particular: ...su poder de protección puesta en los lugares santos, pues es consagrada por Dios.

La Piedra de Coral en polvo fue utilizada por Abulcasis, médico cordobés del siglo $\mathrm{X}$ en la confección de diferentes pastillas medicinales (Arvide Cambra, 1996), y también en la Real Botica del Escorial fundada por Felipe II, como antihelmíntico (gusanos parásitos) y dentrífico. También fue utilizada en veterinaria para la diabetes y como componente de colirios para las enfermedades de la vista (García Cabero, 1755: 120 y 166).

\section{CONCLUSIÓN}

El "Lapidario órfico" es, junto al que contienen los libros XVI y VII de la "Historia Natural" de Plinio y el libro "De lapidibus" de Teofrasto, una de las fuentes escritas más antiguas sobre rocas, minerales y fósiles. A los apoyos históricos aducidos sobre su antigüedad (anterior al siglo II a.C.), se puede ahora añadir que es el único junto al de Plinio que incluye la Piedra Ostrita. Esta queda supuestamente identificada con la Piedra Ostracita en lapidarios más recientes, en los que ya no se encuentra. También es el único, junto a Plinio, que incluye la Piedra de Escorpión.

De este modo, los lapidarios griegos apócrifos, aunque conocidos por copias manuscritas relativamente recientes, parecen contener de una manera críptica las más antiguas descripciones y denominaciones históricas de fósiles; así como datos importantes sobre el significado que las diferentes culturas y épocas dieron a los fósiles. Lo cual se refuerza cuando se analizan comparativamente con otros textos históricos y tradiciones orales que perviven en nuestros días.

La Criptopaleontología, disciplina entendida como "el estudio de las observaciones paleontológicas ocultas en los textos históricos y tradiciones orales de los pueblos" (Liñán, 2004) es, así, una herramienta que nos permite conocer aspectos sobre la historia de la paleontología, pero también de la farmacia, la medicina, de las artes, del comercio y de las religiones; aportándonos no sólo una información valiosa sobre el significado histórico de los fósiles, sino también de la idiosincrasia, creencias, temores y anhelos de las sociedades del pasado.

\section{AGRADECIMIENTOS}

A D. Javier Carrasco Díaz y a D. Vicente Martínez Tejero por sus comentarios a los aspectos farmacológicos de este trabajo. A los profesores Leandro Sequeiros de la Universidad de Granada, Rodolfo Gozalo y Francisco Pelayo de la Universitat de València, y Francisco Marco de la Universidad de Zaragoza por la lectura crítica del manuscrito en sus aspectos paleontológicos, históricos y mitológicos.

Este trabajo es una contribución a los Proyectos BTE 200304997 del Ministerio de Ciencia y Tecnología y E17 del Departamento de Ciencia y Tecnología del Gobierno de Aragón.

\section{BIBLIOGRAFÍA}

Arvide Cambra, L.M.1996. Tratado de pastillas medicinales según Abulcasis. Junta de Andalucía, Almería, $151 \mathrm{pp}$.

Buffetaut, E. 1991. Des fossiles et des hombres. Éditions Robert Laffont, S. A., Paris [Traducción española por P. Galvez. Fósiles y hombres. Ed. Plaza \& Janés, Madrid, 1992, 357 pp.]

Bakhouche, B., Fauquier, F. \& Pérez-Jean, B. 2003. Picatrix. Un traité de magie médiéval. Brepols, Turhount, Bélgica, $383 \mathrm{pp}$.

Calvo Deleán, C. 1990. Opiano: De la caza. De la pesca. Anónimo: Lapidario Órfico. Biblioteca Clásica Gredos, Madrid, 13, 415 pp. 
Cavanilles, A. J. 1795-1797. Observaciones sobre la Historia Natural, Geografía, Agricultura, población y frutos del Reyno de Valencia. La Imprenta Real, Madrid, tomo I, 236 pp., y tomo II, 337 pp.

García Cabero, F. 1775. Instituciones de Albeyteria, y examen de practicantes de ella; divididas en seis tratados, en los que se explican las materias mas essenciales para sus profesores. Oficina de Jofeph de Orga Impresor, Madrid [Facsímil de la Editorial Maxtor, Valladolid, 2001.]

Halleux, R. \& Schamp, J. 1985. Les lapidaires grecs. Collection des Universités de France. Societé d'éditions "Les belles lettres", Paris, 347 pp.

Liñán, E. 1998. Los fósiles y el pensamiento paleontológico. La interpretación histórica de los fósiles. Discurso de ingreso en la Academia de Ciencias Exactas, Físicas, Químicas y Naturales de Zaragoza, 46 pp.

Liñán, E. 2004. Fósiles, mitos y leyendas: Criptopaleontología. Revista de la Real Academia de Córdoba, de Ciencias, Bellas Letras y Nobles Artes, 146, 189-205

Mayor, A. 2000. The First Fossil Hunters. Princeton University Press, Princeton, XX+361 pp. [Traducción española por Martínez i Muntada, R. 2003. El secreto de las ánforas. Edit. Grijalbo, Barcelona, 429 pp.]

Ossendowski, F. 1958. Bestias, Hombres, Dioses. M. Aguilar Editor, Madrid, 287 pp.

Rey Bueno, M. 2002. Los señores del fuego. Destiladores y espagíricos en la corte de los Austrias. Ediciones Corona Borealis, Madrid, 319 pp.
Río, A. M. del 1795. Elementos de Orictognosia o del conocimiento de los fósiles, dispuestos, según los principios de A. G. Wegner, para el uso del Real Seminario de Minería de México. Primera parte que comprehende las tierras, piedras y sales. Impreso en México por Don Mariano Joseph de Zúñiga y Ontiveros, 172 pp. [Edición utilizada: Elementos de Orictognosia. Edición facsímil (ed. J.L. Amorós Portolés). Editoral de la Universidad Complutense, Madrid, 1985.]

Rose, V. 1875. Damigeron de lapidibus. Hermes, 9, 471491.

Taton, R. 1966. La Science antique et médiévale (Des origines á 1450). Presses universitaires de France, París [Traducción española M. Sacristán: Historia General de las Ciencias. 1: Las antiguas ciencias del Oriente. Ediciones, Orbis, Madrid, 1988, 223 pp.]

Torrubia, J. (1754) Aparato para la Historia natural española. Impr. de los herederos de D. Agustín de Gorjuela Sierra, Madrid, 220 pp. [Edición utilizada: Aparato para la Historia natural española (facsímil) (introducción F. Pelayo). Instituto de Geología Económica (C.S.I.C.-Universidad Complutense), Madrid 1994]

Manuscrito recibido: 9 de Diciembre, 2004 Manuscrito aceptado: 9 de Mayo, 2005 